\title{
Bioethics in Bangladesh
}

Prof Hasna Begum, Honorary Professor, Department of Philosophy, Dhaka University.

Email: lala_rukh_selim@yahoo.com

This presentation aims at showing i) poverty level, ii) environmental pollution level, iii) outdated education system, and iv) inadequate health services for over (estimated) 14 crore people in Bangladesh, in order to evaluate the possibility of bioethics practice and research within the country, and also to find the reasons why bioethics activities have not yet found ground here by. Bioethics is a multidisciplinary approach to evaluating bioethical issues. Thus, the main reason for a meager presence of bioethics activities in this country is the education system, which is not multidisciplinary enough to encourage bioethics activities. Apathy among the academicians and professionals in the absence of a national education policy is causing full implementation of a multidisciplinary system impossible. Consequently, students and professionals educated in the present system are generally disinterested in other disciplines. There are bioethical issues present in Bangladesh, e.g., indirect coercion and absence of informed consent in the field of population control, exploitation of people in the name of treatment of infertility, environmental pollution in the absence of law enforcement, exploitation of people by health insurance companies, unethical practices by care-givers in the health sector, etc. In conclusion it is stated that Bangladesh is an untrodden and rich ground for a bioethicist to do research on many relevant issues present in the country. The need for a National Bioethics Association to be formed by academicians and professionals, and a National Bioethics Commission to be formed by the government of Bangladesh has also been emphasized. 